the introduction also, Thomas Kuhn's famous 1959 paper on "Energy Conservation as an Example of Simultaneous Discovery" is criticized largely because Kuhn adopts the stance of the omnipresent narrator rather than playing the role of the contextual historian - should not all good history be contextual? Smith's thesis I found unconvincing.

I also reject his claim that the Universe is fundamentally mechanical in nature. Has he forgotten that Michael Faraday's work on electrolysis, in the 1830s, uncovered the profound fact that electricity comes in units: in atoms. Matter and electricity are inextricably linked. As Richard Feynman once said of this particular discovery by Faraday, it was "one of the most dramatic moments in the history of science, one of those rare moments when two great fields come together and are unified". I was also disappointed that William Grove's work, which gave us the fuel cell, a vitally important means of generating power and energy from matter, is not mentioned. $\square$ John Meurig Thomas is at the Master's Lodge, Peterhouse, University of Cambridge, Cambridge CB2 1QY, UK.

\section{Thinking ahead (and why politicians don't)}

\section{Brain Policy: How the New Neuroscience Changes Our Lives and Our Politics}

by Robert H. Blank

Georgetown University Press: 1999. 199 pp.

$\$ 60(h b k), \$ 21.95$ ( $p b k)$

\section{Joseph T. Coyle}

Government policy is typically formulated by middle-aged bureaucrats and politicians. Experts may be consulted to present the current status of science, but this input is filtered through the policymakers' knowledge base - acquired during their education a quarter of a century or more before. Thus, decisions related to brain and behaviour (affecting policies on substance abuse, mental illness, neurodegenerative disorders and education) are often viewed through the prism of the 1970s, when deviant behaviour was explained by Freudian theory and brain disorders were accepted as incurable tragedies.

Brain Policy is Robert H. Blank's attempt to correct the viscosity of attitude change in response to scientific advances in understanding the brain. A social scientist, Blank became engaged in these issues through his membership between 1987 and 1991 of the US Office of Technology Assessment (OTA) Advisory Panel of Neuroscience Research. The OTA, which performed the important task of informing US government policymakers about scientific advances, was then eliminated as an "unnecessary expense". At least this minimized the confusion that new

\title{
Getting a grip on small things
}

This louse and its offspring hanging onto human hair can be found, along with a host of other oversized creatures, cells, crystals and micromachines, in The Usborne Complete Book of the Microscope by Kirsteen Rogers, edited by Paul Dowswell (Usborne, £9.99). The book won this year's Rhône-Poulenc Junior Science Book Prize and, besides its many revealing pictures, it contains a history of the microscope and instructions on how children can access the world of the microscope for themselves.

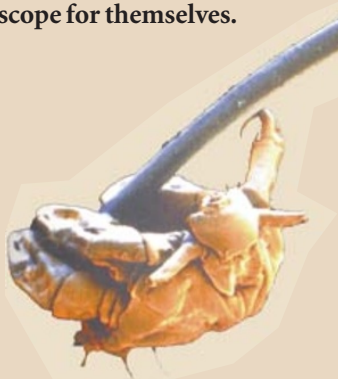

knowledge might have brought to old attitudes in formulating national policy.

Blank is justifiably energized by the remarkable and accelerating advances made in research on brain and behaviour. For example, the Society for Neuroscience grew over 25 years from 400 to 25,000 members in 1996: interest in neuroscience was exploding as the pace of discovery accelerated. Consistent with this growth, the US National Institutes of Health's annual commitments to neuroscience and behavioural research has increased from several hundred million to approximately $\$ 4$ billion over the same period. Not to be ignored is the recent finding that brain disorders account for most of the top ten health conditions, in terms of their economic burden on society.

Brain Policy has some real strengths and a few shortcomings. It is not contaminated by the special pleading of a neuroscientist. Nevertheless, converts can sometimes be more enthusiastic than the original members of a group, a problem Blank avoids by maintaining a critical distance from the Zeitgeist of neuroscience, pointing out the limits and dangers of "excessive exuberance" about therapeutic implications.

The opening chapters - explaining our current understanding of the development, organization and function of the human brain and the interaction among genes, neurons and environment - provide a first-rate introduction to neuroscience for the lay person. Blank condenses remarkably complex material into concepts that are readily grasped, but avoids gross oversimplification.

In later chapters he addresses some of the important policy controversies related to neuroscientific advances, including the current understanding of drug abuse and of behavioural genetics, the ethics of neural grafting and the role of neurotoxins. He artfully side-steps simplistic genetic determinism of behaviour, emphasizing that serious psychiatric disorders are likely to involve complex interactions of several genes of risk with environment. He presents a nuanced discussion of the difficult ethical issues surrounding imposed treatment of psychiatric disorders. He justifiably criticizes the funding agencies for neglecting the study of neurotoxins' contribution to brain disease.

Occasionally, Blank falls into the trap that often occurs in arts and letters, wherein all assertions must be given equal weight. For example, he cites clinical reports that Prozac increased the risk of suicide and violence in depressed patents. While he indicates that the Food and Drug Administration rejected these findings, he does not make it clear that this decision was based on the results of controlled studies that disproved these unfounded contentions. This episode could have provided an instructive example of the distinction between scientific evidence and personal anecdotes; the latter often unfortunately shape policy and legal decisions. But these lapses are infrequent and do not detract from the overall thrust of the book.

Clearly the book is aimed at a general audience, but scientists not conversant with neuroscience would find it an informative, easy read. The first half of the book is redundant to the neuroscientist but the second half — covering policy implications, unintended consequences and ethical concerns - could prove illuminating. For ultimately, in the world of realpolitik, many elements such as ethics and culture play a role: policy is not determined by scientific facts alone. Joseph T. Coyle is in the Department of Psychiatry, Harvard Medical School, Boston, Massachusetts 02115, USA. 